\title{
Promoção de estratégias autorregulatórias com estudantes que apresentam trajetória de insucesso escolar
}

\author{
The promotion of self-regulatory strategies for students that present school failure
}

\author{
Lourdes Maria Bragagnolo Frison *, Ana Margarida da Veiga Simão **, Amélia Rodrigues Nonticuri***, Célia \\ Artemisa Miranda**** \\ * Dra. em Educação, docente do departamento de Fundamentos Psicológicos da Educação, líder do grupo GEPAAR \\ (Grupo de estudos sobre aprendizagem autorregulada), da Universidade Federal de Pelotas, Brasil, \\ ** Professora, Dra. em Educação - Universidade de Lisboa, Portugal, \\ *** Assistente Social, Mestre em Políticas Sociais, Chefe do Núcleo Psicopedagógico de Apoio ao Discente da Pró- \\ Reitoria de Assuntos Estudantis da Universidade Federal de Pelotas, Brasil, \\ **** Mestranda em Educação pelo Programa de Pós-Graduação em Educação da Universidade Federal de Pelotas, \\ Brasil.
}

\begin{abstract}
Resumo
Nesta pesquisa financiada pelo Conselho Nacional de Desenvolvimento Científico e Tecnológico (Cnpq), enfatiza-se que as estratégias autorregulatórias empregadas pelo estudante para aprender podem promover a superação do fracasso escolar, conforme estudo realizado com duas alunas do Ensino Superior com históricos que evidenciam reprovações no decorrer do período acadêmico. Tais alunas participaram do Grupo Psicossocial de Atenção à Aprendizagem desenvolvido pela Universidade Federal de Pelotas, Brasil. Os instrumentos utilizados foram: entrevista antes e após o trabalho em grupo, materiais elaborados no último encontro e análise dos históricos acadêmicos das estudantes. $\mathrm{O}$ estudo fundamentou-se nos pressupostos do constructo da autorregulação da aprendizagem.
\end{abstract}

Palabras clave: autorregulação, estratégias, insucesso escolar.

\begin{abstract}
In this research, funded by the National Council for Scientific and Technological (Cnpq), it is emphasized that the self-regulatory strategies used by the student to learn can promote the overcoming of school failure, according to a study carried out with two students of higher education with historical of failures during the academic period. These students participated in the Group of Psychosocial Care Learning developed by the Federal University of Pelotas, Brazil. The instruments used were interviews before and after the group work, materials prepared at the last meeting and analysis of academic records of students. The study is based on the construct of the assumptions of self-regulation of learning.

Keywords: self-regulation, strategies, school failure
\end{abstract}

Neste artigo pretende-se abordar a promoção de estratégias autorregulatórias com estudantes que apresentam trajetória de insucesso escolar a partir do estudo de caso de duas alunas do Ensino Superior com históricos que evidenciam várias reprovações no decorrer do período acadêmico, participantes do grupo de promoção da aprendizagem aos alunos com insucesso escolar, promovido pelo Núcleo Psicopedagógico de Apoio ao Discente da Pró-Reitoria de Assuntos Estudantis da UFPel.

Miguel, Rijo e Lima (2012) apontam que a literatura atribui três categorias que influenciam significativamente o sucesso escolar dos alunos, nomeadamente a família, a escola e as características individuais do aluno. Posto que a escola e a família são fatores externos ao aluno, estáticos e pouco controláveis, com potencial de mudança reduzido (Weiner, 1985), se evidencia o papel ativo do aluno no seu processo de aprendizagem, procurando interferir no fatores pessoais para alcançar o seu sucesso escolar. Destacando variáveis cognitivas, motivacionais, comportamentais, entre outros, Miguel, Rijo, Lima (2012), afirmam que essas variáveis podem ser determinantes para o sucesso escolar dos alunos, quando estes acreditam na sua auto-eficácia escolar, autorregulam sua aprendizagem, ou mantém relações interpessoais e de integração social.

Os alunos ao trabalharem desenvolvendo suas competências individuais, auxiliados pelas teorias sociocognitivistas, que propõe um processo de mediação cognitiva entre o aluno e o seu desempenho na tarefa, modificam positivamente suas crenças de auto-eficácia e atribuições causais, refletindo em seus resultados, expectativas ou metas. Com base na teoria das atribuições causais de Weiner (1985), estudos têm revelado que os alunos têm atribuído o seu insucesso escolar a variáveis pessoais como a capacidade e o esforço, apostando no seu potencial de desenvolvimento cognitivo e metacognitivo, por meio de sua autorregulação da aprendizagem (Borunchovithc, 1999).

O construto da autorregulação, apesar de ainda não se constituir como uma teoria definida tem sido subsidiada por diversas abordagens teóricas (Souza, 2006), como a 
Comportamental, Fenomenológica, Volitiva, Construtivista, Vygotskiana e sociocognitiva (Abrahão; Frison, 2012). A abordagem sociocognitiva neste estudo foi utilizada por acreditar que, dentre as demais, ela oferece o suporte necessário para a compreensão do construto da autorregulação.De acordo com seu proponente, Zimmerman (1989) a autorregulação pode ser definida como o nível em que os estudantes participam no seu processo de aprendizagem sob os aspectos motivacionais, metacognitivos e comportamentais (Zimmerman, 1989, p.137). A autorregulação é um processo pelo qual o sujeito cria estratégias de auto-organização e define metas capazes de levá-lo a atingir os resultados pretendidos (Abrahão; Frison, 2012). Os alunos autorregulados usam "processos específicos que transformam suas habilidades preexistentes em comportamentos relacionados à tarefa, em diversas áreas de funcionamento" Zimmermam (2013, p.137). Nesse processo ativo e construtivo, o aluno é instigado a definir objetivos baseados em suas expectativas e motivações, regulando suas estratégias para buscar novos conhecimentos. Os estudantes desenvolvem autonomia diante do seu processo de aprendizagem, criando seus próprios métodos de organização nas dimensões cognitivas, metacognitivas e motivacionais, inseridos em um contexto.

Para Zimermman (2013, p. 142), a autorregulação da aprendizagem compreende três fases cíclicas que se influenciam entre si, completando o ciclo autorregulatório.

A primeira, definida como Fase da Antecipação, refere-se às influências, crenças motivacionais, metas e estratégias criadas para aprender um determinado conteúdo, ou fazer uma determinada ação. A segunda fase - Execução refere-se ao esforço e ao empenho do sujeito nas estratégias criadas para a efetivação da aprendizagem e afetam a concentração e a execução. Por último, a terceira fase - autorreflexão, visa à autoavaliação realizada pelo próprio sujeito (Zimmerman, 1998; Abrahão; Frison, 2012)

A Fase de Antecipação envolve duas categorias: a análise da tarefa e as crenças motivacionais. Durante a análise da tarefa, é necessário que os alunos, não se prendam a uma análise superficial, estabelecendo métodos vagos de aprendizagem, como se esforçar mais ou se concentrar mais. É preciso haver uma análise efetiva da tarefa, planejando estratégias mais eficientes que os auxiliem na aprendizagem (Zimmerman, 2013). As estratégias criadas pelos alunos devem considerar o planejamento e ajuste segundo suas condições pessoais, comportamentais e ambientais.

As motivacionais compreendem as crenças de autoeficácia, as crenças de expectativas de resultados e as crenças do valor intrínseco. As crenças de auto-eficácia dizem respeito ao julgamento que o aluno faz de sua capacidade para aprender ou de realizar determinada tarefa (Bandura, 1986); as crenças de expectativas de resultados são as crenças sobre o resultado do seu desempenho; e as crenças do valor intrínseco abordam o continuo esforço na realização da tarefa mesmo na ausência de recompensa (Zimmerman, 1998).

As crenças de auto-eficácia influenciam o estabelecimento de metas e os subprocessos da autorregulação da aprendizagem, como o automonitoramento, o gerenciamento do tempo, o uso de estratégias e a autoavaliação (Zimmerman; 1998). Assim, é importante promover experiências diretas, modelos sociais de sucesso, feedback positivo e estratégias cognitivas para fortalecer no estudante a sua percepção de auto-eficácia, permitindo dessa forma, maior envolvimento no processo de autorregulação da aprendizagem (Zimmerman; 1998; Salgado, 2013).

A Fase de Execução acontece durante a realização da tarefa e é planejada na Fase de Antecipação considerando a capacidade do aluno de autocontrolar e de se auto-observar durante o processo de aprendizagem. $\mathrm{O}$ estudante pode adquirir autocontrole por meio da autoinstrução, ou seja, falar para si mesmo como proceder enquanto realiza a tarefa (Zimmerman, 1998). Outras formas de autocontrole seriam as representações mentais, auxiliadas pela autorrecordação; a atenção focada para minimizar os distratores, e o uso de estratégias para reduzir a tarefa complexa em partes essenciais, como: sublinhar, anotar, gerenciar o tempo, resolver problemas, estabelecer metas, usar gráficos, entre outras. Quando o estudante se auto-observa, efetua um monitoramento metacognitivo de gerenciamento do seu desempenho, e autorregistro, apontando notas formais para a compreensão da tarefa.

$\mathrm{Na}$ Fase da Autorreflexão, que compreende os processos que acontecem depois da aprendizagem e influenciam as reações do aluno, e ocorre por meio do autojulgamento e da autorreação. $\mathrm{O}$ autojulgamento decorre da autoavaliação, que se dá a partir da comparação das informações sobre o seu automonitoramento com as metas e a atribuição causal. A vantagem da comparação está vinculada à possibilidade de mudanças no seu funcionamento. $\mathrm{O}$ estudante pode reagir por duas razões: pela autossatisfação ou pelas inferências adaptativas. A autossatisfação envolve a percepção de satisfação e insatisfação do aluno, que estão relacionadas ao seu próprio desempenho e interfere nos autoincentivos. As inferências adaptativas são conclusões de como o sujeito precisa modificar o enfoque de sua autorregulação conforme o esforço para aprender ou desempenhar. As inferências defensivas irão proteger o aluno de eventos futuros que desencadearão a insatisfação e a aversão, como a procrastinação, a evitação da tarefa, o desengajamento cognitivo, a apatia e o desamparo (Zimmerman;1998). As autorreações afetam os processos antecipatórios de maneira cíclica e interferem em futuras ações, reforçando o processo de autorregulação da aprendizagem (Zimmerman, 1998; 2013)

A partir da compreensão das fases da autorregulação, pode-se dizer que o aluno que autorregula sua aprendizagem é aquele que potencializa seu esforço 
durante a aprendizagem, pois descobre quais processos funcionam melhor para ele, o que justifica o papel de automonitoramento e outros processos autorregulatórios (Zimmerman; 1998)

\section{Método}

Este artigo é decorrente de uma pesquisa qualitativa, tendo como metodologia um estudo de caso (GIL, 2006), nele procurou-se analisar o processo autorregulatório de duas alunas do ensino superior que participaram do Grupo Psicossocial de Atenção à Aprendizagem, durante o segundo semestre de 2014. Estas alunas apresentam um quadro de baixa percentagem de aprovação $(<70 \%)$ em quase todos os semestres já cursados, o que é caracterizado por nós como fracasso escolar. Os alunos que se encontram em tal condição, são encaminhados pela Coordenadoria de Integração Estudantil para o NUPADI, pois correm o risco de terem seu beneficio estudantil, como auxílio alimentação e transporte, suspenso em razão de não terem alcançado $70 \%$ de aprovação. No Núcleo os alunos serão convidados a participarem do Grupo Psicossocial de Atenção à Aprendizagem, composto por quinze alunos no máximo, que compreende uma programação de dez encontros temáticos, de três horas cada um, que acontecem quinzenalmente no decorrer do semestre. O NUPADI tem como objetivo principal oferecer recursos de ordem psicossocial aos alunos com fracasso acadêmico proporcionando atendimento individual e grupal. Ao chegar no NUPADI, o aluno ao ser acolhido, passa por uma entrevista com um dos profissionais da equipe. Após, assina o termo de compromisso no qual se compromete a participar dos dez encontros previstos para o grupo. Cada encontro, com duração de três horas, aborda um tema, escolhido a partir das necessidades dos alunos que participaram das entrevistas, que geralmente são: atenção e concentração, memória, técnicas de estudos, apresentação oral de trabalhos acadêmicos, autoconhecimento, motivação, controle emocional e ansiedade, leitura e escrita, desinibição e oratória e o último encontro é uma revisão de todos os outros. Neste trabalho, destacam-se as atividades realizadas no último encontro, que serviram de análise para este estudo. Neste último encontro, os alunos tinham que refletir e se expressar por intermédio de cartões, respondendo as seguintes perguntas: aonde quero chegar, o que preciso fazer, quais são minhas dificuldades, o que faço para me motivar?

Inicialmente os alunos receberam orientação sobre o trabalho que seria desenvolvido, no qual para cada pergunta eles poderiam escrever nos cartões as suas respostas que após seriam coladas na parede para permitir melhor visualização do pensamento ao grupo.

A primeira pergunta: Aonde quero chegar? intencionava identificar as metas de cada um, que poderiam ser de ordem pessoal, profissional, acadêmica, desde que fossem relacionadas ao seu processo de aprendizagem na universidade. Cada aluno poderia citar até três objetivos/metas. A segunda pergunta: $O q u \hat{e}$ preciso fazer? - referia-se às estratégias que cada um utilizaria para alcançar seus objetivos. Da mesma forma, cada aluno foi convidado a escrever três estratégias e depois colar na parede, apresentando-a oralmente ao grupo, desencadeando uma reflexão sobre sua escolha. A terceira pergunta: Quais são as minhas dificuldades? - buscava identificar as fragilidades dos alunos em relação ao seu processo de aprendizagem com o objetivo de contribuir para o planejamento dos próximos encontros do grupo. A quarta pergunta: $O$ que faço para me motivar? - procurou identificar os recursos internos e externos que impulsionam os alunos a continuarem seus estudos apesar das dificuldades encontradas.

Dos 15 alunos que compunham o Grupo durante o segundo semestre de 2014, foram selecionadas duas alunas (Ana e Bruna, nomes fictícios), por terem participado em todas as atividades do grupo. A aluna Ana encontra-se matriculada no curso de Química Industrial bacharelado da UFPel e a Bruna no curso de Química bacharelado da UFPel, e ao mesmo tempo concluindo o curso técnico em Química no Instituto Federal Sul Rio-Grandense - IFSul.

Para além dos cartões recolhidos no encontro do grupo, realizaram-se entrevistas antes e depois da intervenção grupal e analisou-se o histórico escolar das alunas ao longo do curso.

\section{Resultados}

A entrevista com as alunas consistiu na primeira ação do NUPADI assim que elas chegaram ao Núcleo, encaminhadas pela Coordenadoria de Integração Estudantil. A entrevista inicial trouxe dados importantes sobre o contexto, motivação, aspectos cognitivos das alunas que caracterizavam a situação de fracasso escolar na qual se encontravam.

A aluna Ana, 24 anos, não trabalha e não tem filhos. Mantém bom relacionamento com professores, colegas e familiares. Nas horas de folga prefere ficar em casa assistindo programas de televisão. Geralmente dorme tarde, em torno de $1 \mathrm{~h}$ ou $2 \mathrm{hs}$ da madrugada, dormindo em torno de sete horas diárias. Este fato faz com que ela sinta sono no dia seguinte, principalmente durante a manhã. Ainda referiu que sua alimentação não é saudável,muitas vezes não almoça, não toma café de manhã, come toda hora um pouco, e gosta de frutas. Costuma ter enxaquecas e para isso consultou um especialista que lhe receitou uma medicação. A aluna não pratica exercícios físicos. Sua maior preocupação é o medo de nunca se formar e o significado que atribui à sua formação acadêmica enquanto projeto para o futuro consiste em uma conquista em sua vida.

Constatou-se que a aluna tinha poucas atividades de lazer, hábitos de sono e alimentação que poderiam estar contribuindo negativamente para seu desempenho acadêmico. Sabe-se que alguns estudos comprovam a importância desses fatores para a aprendizagem, memorização e concentração (Izquierdo, 2008). Durante os encontros procurou-se fazer os alunos refletirem sobre que se dormirem, se alimentarem melhor, realizando atividades de lazer e prática de exercícios físicos, poderão ter mais sucesso na aprendizagem. Quanto ao desempenho escolar da aluna Ana, no Ensino 
Fundamental era bom, mas do Ensino Médio para cá começou a ter problemas de concentração e hiperatividade. Sobre seus hábitos de estudo, Ana procura estudar todos os dias, quando chega em casa, fazer as listas de exercícios, ler os slides referentes ao conteúdo das disciplinas, mas não consegue entender a matéria. No período de provas, tenta estudar por um período maior de tempo durante o dia, mas não consegue reter a informação. Segundo ela, o seu fracasso acadêmico faz com que ela se sinta "burra", sem condições de aprender. Na sua opinião, o que a faz se sair bem em uma prova é quando tem só uma prova para realizar no dia, porque sente que tem a tendência a se confundir entre os conteúdos das diferentes disciplinas. Na época da entrevista, a aluna referiu ter frequentado todas as aulas. Dentre as disciplinas que mais reprovou está o Cálculo II, na qual se matriculou três vezes e ainda não obteve aprovação. Alega não entender a utilidade dessa disciplina, além de ter dificuldades com Física.

Bruna tem 21 anos, não trabalha e não tem filhos. Mantém bom relacionamento com professores, colegas e familiares. Nas horas de folga, gosta do ócio e de visitar os pais que moram na zona rural. Geralmente dorme bem, em torno de oito horas diárias, mas mesmo assim costuma sentir sono durante o dia. Bruna referiu que sua alimentação é saudável, não apresenta problemas de saúde, costuma ir ao médico quando está doente, não pratica exercícios físicos. Seu desempenho escolar no Ensino Fundamental e Médio sempre foi bom, e nunca reprovou. Sobre seus hábitos de estudo Bruna procura estudar apenas nos dias em que não tem aula e nos outros dias repassa a matéria e faz os exercícios. No período de provas, procura estudar com uma semana de antecedência. No momento da prova costuma se sentir mal, como se não soubesse nada sobre o conteúdo da disciplina, uma impressão de não ter estudado o suficiente. Na sua opinião, o que a faz se sair bem em uma prova é a certeza de ter feito os exercícios. Na época da entrevista, a aluna referiu ter faltado muito às aulas por motivo de doença de um familiar. Sua maior preocupação é o medo de reprovar mais uma vez nas disciplinas que já reprovou, por isso o significado que atribui à sua formação acadêmica enquanto projeto para o futuro é de ter orgulho por conseguir concluir o curso.

Verificou-se o impacto que as alunas sentiram na transição entre o Ensino Médio e o ingresso na Universidade. Mesmo esforçando-se e estudando todos os dias, apresentavam dificuldades na compreensão da matéria e de sua utilidade para a formação profissional. Nesse sentido, Ana referiu que sentia-se incapaz para a realização da tarefa e não via utilidade nas disciplinas, abalando sua crença de auto-eficácia e a crença do valor intrínseco da tarefa (ZIMMERMAN,1998), as quais não correspondiam ao que estava significando no momento. Segundo estudos de Pintrich (1999) e Wigfield (1983) o valor da tarefa constitui-se em fonte de motivação, pois em seus componentes (utilidade, importância e interesse) encontram-se a sustentação sobre a qual o aluno poderá direcionar esforços de criar estratégias para autorregular sua aprendizagem (SOUZA, 2010). Já no caso de Bruna, o impacto se deu na diferença do resultado que obtinha no ensino fundamental e médio, que era bom, para o resultado na universidade, que se configurou como fracasso escolar. Antes de seu ingresso na universidade, nunca havia reprovado, o que abalou sua crença de auto-eficácia. De acordo com Bzuneck (2001), fracassos repetidos contribuem para um senso mais pobre de auto-eficácia, o que levanta preocupação, já que a literatura revela que baixas crenças de autoeficácia refletem negativamente no desempenho escolar.

É possível visualizar que as alunas atribuem o fracasso a sua falta de capacidade e de esforço, assim como é evidenciado em vários estudos (Figueira; Lobo, 2012; Almeida; Miranda; Guisande, 2008; Martini; Prette, 2005), embasadas pela Teoria das Atribuições Causais de Weiner (1985).

Ao analisar o histórico escolar dessas alunas observase as frequentes reprovações e desistências ao cursar as disciplinas matriculadas, trancando-as ou mesmo não frequentando as aulas.

Das 35 disciplinas matriculadas desde o semestre 2010/2 até 2014/1 Ana obteve aprovação em apenas 15 disciplinas (46\%). Nesses oito semestres de curso, a aluna se matriculava em média em 4 disciplinas por semestre, mas aprovava em média em apenas duas. No semestre de 2014/2 a aluna se matriculou em 7 disciplinas, trancando uma. Segundo a aluna, este fato se deve à sua motivação e modificação da crença de auto-eficácia que possibilitou a sua decisão em aumentar o número de disciplinas cursadas contribuindo para acelerar o tempo de conclusão do seu curso.

Quanto à Bruna, apesar de estar no $4^{\circ}$ semestre, seu histórico escolar, já levanta preocupações, visto que das 14 disciplinas que ela se matriculou de 2012/2 a 2014/1 obteve aprovação em apenas duas delas. Isto é, com uma média de 3 a 4 disciplinas matriculadas por semestre, esta aluna obteve várias reprovações em cada semestre, intercaladas com as infrequências e trancamentos. Nesse último semestre se matriculou em apenas duas disciplinas, uma vez que concomitante à sua formação na UFPel, a aluna também estava cursando as últimas disciplinas que lhe possibilitariam concluir o curso técnico de Química, no IFSUL.

A análise do histórico escolar das alunas se faz necessário para compreender como a partir dos encontros do grupo, as alunas melhoram a dimensão motivacional, no que concerne às crenças de autoeficácia, valor da tarefa e expectativa de resultado.

Nos semestres anteriores, Ana se matriculava em média em 4 disciplinas por semestre. No entanto, a partir do segundo semestre de 2014, após ter passado pelas primeiras sessões do grupo, a aluna se encorajou e matriculou-se em 7 disciplinas. No relato da entrevista, afirmou que se sente melhor neste semestre, mais confiante, com maior motivação para continuar o curso. Das seis disciplinas que está cursando, já obteve aprovação em duas e ficou em exame em quatro delas. No entanto afirma que desta vez, necessita de uma nota mais baixa para passar, do que nos semestres anteriores. No momento da entrevista, a aluna estava na semana de exames, e já tinha feito um, do qual disse ter saído com 
boa perspectiva sobre seu resultado. Ana ainda relatou que neste semestre está se saindo bem melhor e acha que sua participação no grupo a ajudou muito, principalmente ao utilizar estratégias para se concentrar, embora ainda se perceba com necessidade de aprimorar sua atenção e concentração. Ao final do semestre, Ana alcançou aprovação em todas as disciplinas para as quais prestou exame, atingindo suas metas.

Quanto a Bruna, apesar de ter se matriculado em apenas duas disciplinas neste semestre, apresentou aprovações importantes, tanto nas duas disciplinas do seu curso na UFPel, como nas disciplinas que cursava no IFSul, chegando a concluir o curso técnico de química. Referiu que conseguiu aprovação devido às estratégias que utilizou e que aprendeu no grupo, como não deixar para estudar de última hora, a utilizar as técnicas de relaxamento, conseguindo se manter mais calma no momento das provas, mais confiante, prestando mais atenção e acreditando mais em si. No último semestre, 2014/2, a aluna alcançou metas importantes, principalmente nos indicadores de aprovações e média geral, reduzindo a zero os indicadores de reprovações, trancamentos e infrequência, iniciando uma tendência positiva em seus resultados.

\section{Discussão}

Como foi relatada pelas alunas, grande parte do sucesso obtido neste semestre se deve ao fato de refletirem sobre suas possibilidades, utilizando as estratégias autorregulatórias, conforme foram trabalhadas durante os encontros com o grupo. A participação das alunas nos encontros promovidos pelo NUPADI mostrou-se fundamental nesse processo, oportunizando o acesso a informações, vivências, reflexões, troca de experiências, espaço para criação de estratégias e acompanhamento.

Os resultados evidenciaram que as alunas tornaram-se estudantes mais autorregulados para a aprendizagem, visto que tornaram-se mais ativas, autônomas, capazes de controlarem seu processo de aprendizagem, conhecendo suas potencialidades e limitações e criando formas de lidar com elas. As alunas conseguiram melhorar seus níveis de aprovação e principalmente aprenderam a lidar com seus próprios recursos internos e externos, aumentando sua autoconfiança autocontrole, automonitoramento, autoobservação, autorreflexão, recursos importantes para manterem-se protagonistas na gestão do processo de aprendizagem.

\section{Referências}

Almeida, L.S., Miranda, L. \& Guisande, M. A.(2008). Atribuições causais para o sucesso escolar. Estudos de Psicologia. v.2. n.25. abr. - jun. (pp.169-179). Campinas.

Angelucci B .C., Kalmus, J., Paparelli, R. \& Patto, M.S. (2004). O estado da arte da pesquisa sobre o fracasso escolar (1991- 2002). In: um estudo introdutório .
Educação e pesquisa, v.30, n.1, (pp.51-72), jan.abr. São Paulo.

Bzuneck, J. A. (2001). As crenças de auto-eficácia e o seu papel na motivação do aluno. In J. A. Bzuneck \& E. Boruchovitch (Orgs.), A motivação do aluno: contribuições da Psicologia contemporânea (pp. 116133). Petrópolis: Vozes.

Figueira, A. P. C. \& Lobo, R. C.T. (2012). A triologia atribuições causais, concepções pessoais de inteligência e mensagens de feedback: um contributo para a compreensão do fracasso escolar. Praxis Educacional. v.8, n.13. (pp.83-105). Vitoria da Conquista.

Gualtieri, C. E. \& Lugli, R.G (2012).. A escola e o fracasso escolar. Coleçao educação e saúde; v.6. São Paulo: Cortez.

Izquierdo, Iván. (2008) Memória. Porto Alegre: Artmed, Martini, M. \& Prette, Z. A. P. (2008). Atribuições de causalidade e afetividade de alunos de alto e baixo desempenho acadêmico em situações de sucesso e de fracasso escolar. Revista Interamericana de Psicologia/InteramericamJournalofPsycollogy. N.3. v.39 (pp.355-368).

Miguel, R. R., Rijo, D., \& Nobre Lima, L. Fatores de risco para o insucesso escolar: a relevância das variáveis psicológicas e comportamentais do aluno. Revista Portuguesa de Pedagogia, v.46, n.1, 2012. (pp.127-143)

Patto, M.H.S. (1990). A Produção do Fracasso Escolar: histórias de submissão e rebeldia. São Paulo : T. A. Queiroz.

Pintrich, P. R. (1999). The role of motivation in promoting and sustaining self-regulated learning. In: International Journal of Educationa lResearch, v. 31, (pp. 459-470)

Souza, L. F. N. I.(2010). Estratégias de aprendizagem e fatores motivacionais relacionados. Educar, n. 36. (pp. 95-107). Curitiba: Editora UFPR.

Sousa, P. M. L. (2004). Aprendizagem Autorregulada no Contexto Escolar: uma abordagem motivacional. Coimbra.

Disponível em: http://www.psicologia.pt/artigos/textos/A0295.pd f. Acessoem: 15 nov. 2014

Weiner, B. (1985). An atribucional theory of achievement, motivation, and emotion. In: Psychological Review, v.92,n.4, (pp.548-573).

Wigfield, A. \& Eccles, J. S. (2000). Expectancy-Value Theory of Achievement Motivation. In: Contemporary educational Psychology, v. 25,(p p. 6881).

Zimmerman, B. (1998). Developing self-fulfilling cycles of academic regulation: na analysis of exemplary instructional models. In. D. Schunk, \&, B. Zimmerman. Self-regulated learning: from teaching to self-reflective practice. (pp. 1-19). New York: The Guilford Press.

Zimmerman, B. (2013). From cognitive modeling to self-regulation: a social cognitive career path. Educationalpsychologist, v.48, n.3, (pp.135-147). 